\section{CIVIL SOCIETY SUPPORTING GOVERNMENT IMPLEMENTATION OF THE ROAD TRAFFIC LAW IN CAMBODIA}

${ }^{1}$ Sinthay Neb, ${ }^{2}$ Sophal Khem, ${ }^{3}$ Bunthan Tep. ${ }^{1}$ Advocacy and Policy Institute; ${ }^{2}$ Cambodian Red Cross; ${ }^{3}$ Women's Media Centre

10.1136/injuryprev-2016-042156.140

Background In January 2015, the King of Cambodia signed the new Road Traffic Bill into law. The RTL addresses drinking and driving, speeding, helmet use, and other road safety issues. Implementation of the law is an important component of reducing road traffic crash-related injuries and deaths.

Description of the problem As road safety good practice suggests, legislation without comprehensive implementation campaigns will not result in impactful reductions of road traffic death and injury. In Cambodia, district level implementation of the Road Traffic Law is necessary to achieve intended reductions of road traffic death and injury.

Results A coalition of civil organisations led by the Advocacy and Policy Institute (API) partnered with the government to effectively implement the national law at the district level. API worked with 12 district governments to allocate road safety funds and integrate the road safety law into district development plans. The Cambodian Red Cross utilised its seat on the National Road Safety Committee to maintain strong national-level support for the Road Traffic Law among policy-makers and enforcement agencies. Lastly, the Women's Media Centre launched a public awareness campaign about the importance of the law and safe practice for road safety.

Conclusions API and other civil society organisations effectively supported local implementation of Cambodia's national law. Without the added civil society resources, the general public would not have been sufficiently aware of the new legislation, its underlying rationale, or penalties. Likewise, sufficient attention to implementation of the new legislation may not have been paid in the finalisation of district development plans and other legislative implementation platforms.

\section{UNDERSTANDING SPEEDING BEHAVIOUR AMONG OMANI DRIVERS USING THEORY OF PLANNED BEHAVIOUR}

${ }^{1}$ Ali Al Azri, ${ }^{2}$ Abdullah Al Maniri, ${ }^{3}$ Ibrahim Al Harthy, ${ }^{4}$ Lucie Laflamme, ${ }^{5}$ Marie Hasselberg. ${ }^{1}$ Ministry of Health, Oman; ${ }^{2}$ The Research Council, Oman; ${ }^{3}$ Sultan Qaboos University, Oman; ${ }^{4}$ Karolinska Institutet, Sweden; ${ }^{5}$ Karolinska Institutet, Sweden

\subsection{6/injuryprev-2016-042156.141}

Background Oman has one of the highest road traffic fatality rates in the world. Speeding behaviour has been recognised as one of the most important risk factor in fatal road traffic crashes (RTCs) in the Sultanate of Oman in the year 2011. The aim of this study was to identify factors that are associated with selfreported speeding behaviour based on the Theory of Planned Behaviour (TPB).

Methods The study was cross sectional. A total of 1800 Omani male drivers in the age range of $17-45$ years were recruited during March 2013 from directorate of vehicle registration using systematic random sampling technique based on their seat number. A questionnaire was developed and used to collect data concerning socio-demographic characteristics, driving behaviour, driving history and the subscales of TPB. The questionnaire was assessed for validity and reliability. Multivariate logistic regression was used to examine the association between the constructs of TPB and speeding behaviour.

Results The response rate was $71.4 \%$. The mean age was $29 \pm 6.6$ (mean \pm standard deviation) years. Only $14 \%$ $(n=174)$ of the drivers reported that they never or very rarely exceeded the speed limit when given the chance. The drivers with younger age, having children, high monthly income, having motoring and speeding offences were more likely to speed compared to other drivers. The odds of speeding among those who said their speed was "much faster" compared to other drivers was 4.7 (Odds Ratio (OR) $=4.7,95 \%$ CI: 1.6, 13.8). Around $46 \%$ of the sample had got speeding offences. Speeding behaviour is significantly predicted by attitude and subjective norms. Speeding behaviour is significantly predicted by intention to respect the speed limits $(\mathrm{OR}=0.72,95 \% \mathrm{CI}: 0.72,0.76)$ and by attitude, subjective norms and perceived behavioural control.

Conclusions Speeding behaviour is common among male Omani drivers and the TPB can be used to understand the factors associated with it.

\section{RISK FACTORS AMONG HEAVY VEHICLE DRIVERS}

${ }^{1}$ Lakshmi C Somatunga, ${ }^{2}$ Upali Karunarathne. ${ }^{1}$ Ministry of Health, Sri Lanka; ${ }^{2}$ Provincial Health Office, Southern Province, Sri Lanka

\subsection{6/injuryprev-2016-042156.142}

Background Since 1995, Traumatic injuries remain as the leading cause of hospitalisation in Sri Lanka for consecutive years. Among traumatic injuries, road traffic injuries are leading. It accounts for $22 \%$ to $25 \%$ of all types of injuries. For both fatal and non-fatal Road Traffic Injuries (RTI), heavy vehicles are involved frequently. It was revealed from the statistics available at National Transport Medical Institute (NTMI) in Colombo, Western Province of Sri Lanka that $10.38 \%$ of heavy vehicle drivers met with accidents were found medically unfit for driving and they face a number of risk factors. The study was undertaken with the objective of describing the risk factors and occupational health hazards among heavy vehicle drivers.

Methods A descriptive cross sectional study design was adopted with a systematic random sample of heavy vehicle drivers attending to renew driving licenses at NTMI, the national institute with its branches responsible for conducting medical examination of heavy vehicle drivers enabling them to obtain or renewal of driving licenses in Sri Lanka during a period of one month. Data were collected using a questionnaire and a document review (medical examination and investigations) using a check list.

Results The majority of heavy vehicle drivers in study population comprise young male drivers with a mean of 33.9 years. They work for extended period of time (mean working duration is 11.3 hours). The study showed a clear evidence of high incidence of Gastro Esophageal Reflux Disease and Gastritis $(13.8 \%)$. The conditions like impaired distance vision $(4.4 \%)$ Hypertension (0.8\%) and Diabetes Mellitus (1.2\%) were also found. Nonspecific backaches and pains (10.9\%) and chronic cough $(9.7 \%)$ were common complaints. The habits of cigarette smoking (45.1\%), beetle chewing (34.9\%) and alcohol consumption $(60.5 \%)$ were obviously high, compared to national level. The leading occupational health hazards encounter with heavy vehicle driving were identified in the study. They included frequent exposure to diesel exhaust (8.5\%), overload vehicle (26.8\%), uncomfortable gear lever operation (13\%), uncomfortable foot pedals (14.6\%), uncomfortable steering wheel operation 
(17\%) and driving seat vibration (10.1\%). The options available in vehicles for drivers comfort looked insufficient in most of the heavy vehicles (availability of Air Conditioning (4.8\%), Automatic gear transmission $(0.8 \%)$ and availability of head rest in driving seat $(43.4 \%)$ were not adequate. The emerging hazard of "inattention blindness" in driving due to use of cell phones while driving (18.2\%) was also noted among Sri Lankan heavy vehicle drivers in significant level.

Conclusions The study shows that road safety research needs to go beyond common RTI risk factors and analyse risks involved with the health status of drivers. And it suggests that strengthening of quality control of heavy vehicles, health education and regular monitoring of health status of heavy vehicle drivers is vital to improve the status of countries injury prevention efforts.

\section{INVESTIGATING CHARACTERISTICS OF WORK ZONE AND NON-WORK ZONE CRASHES ON NATIONAL HIGHWAY-8, INDIA}

Sumeet Gupta, Abhaya Jha, Geetam Tiwari. Indian Institute of Technology Delhi, New Delhi, India

\subsection{6/injuryprev-2016-042156.143}

Background The continuously increasing number of road construction and maintenance projects in India, especially on highways, creates huge risk for road users. This prompted us to examine the difference between characteristics of fatal crashes in Work Zones (WZs) and Non-Work Zones (NWZs).

Methods The study included analysis of fatal crash data for the period November 2009 to December 2013. Crash parameters such as the date, time, collision type, type of victim, i.e., pedestrian/cyclist/car user, etc., victim's age, vehicle type, number of persons injured/killed etc., were extracted from fatal crash records. WZ crashes were extracted from the main crash database. The design chainage, length, start date and end date of each WZ was obtained from the concessionaire.

Results The crash rate is higher in WZs (1.68 crashes $/ \mathrm{km} / \mathrm{year})$ as compared to Non-WZs (1.32 crashes $/ \mathrm{km} / \mathrm{year}) .77 \%$ and $71 \%$ of WZ and NWZ fatalities respectively involved vulnerable road users (pedestrians, bicyclists and motorised two wheeler riders) as victims. A higher proportion of working age group people (2660 years) are involved in both WZs (46\%) and NWZs (48\%). Fatal crashes in both WZs and NWZs are more likely to be involved with another vehicle (nearly 95\%). "Hit pedestrian" crashes were the dominant type in both WZs (41\%) and NWZs (39\%). Trucks are involved (as a striking vehicle) in a higher proportion of fatalities in both WZ (52\%) and NWZ (54\%) locations.

Conclusions The proportion of fatalities and fatal crashes are very similar in both WZs and NWZs but the rate of fatal crashes is comparatively higher in WZs. The predominance of hit pedestrian crashes, especially, in WZs, strongly indicates that one of the causal factors is over speeding. The implementation of a countermeasure like rumble strips that forces drivers to drive at approximately the same speeds throughout the WZs will improve safety at WZs significantly.

\section{ROAD TRAFFIC INJURY MORTALITY, MORBIDITY AND DISABILITY: EVIDENCE FROM BANGLADESH HEALTH AND INJURY SURVEY (BHIS)}

${ }^{1}$ Baset Md Kamran ul, ${ }^{1}$ Rahman Aminur, ${ }^{1}$ Mashreky Saidur Rahman, 'Talab Abu, 'Rahman AKM Fazlur, ${ }^{2}$ Towner Elizabeth. ${ }^{1}$ Centre for Injury Prevention and Research, Bangladesh (CIPRB): ${ }^{2}$ University of the West of England

\subsection{6/injuryprev-2016-042156.144}

Introduction Road traffic injuries (RTIs) are a leading cause of morbidity, disability and mortality in low income countries. In 2004 nearly 1.3 million people of all ages were killed in road traffic crashes and over 50 million were injured or disabled. There are indications that road traffic injury fatalities and morbidities are increasing in Bangladesh.

Objective Investigate the magnitude of and risk factors for road traffic injury in Bangladesh.

Methodology A cross sectional study was conducted to explore the magnitude of mortalities and disabilities due to RTIs. Face-toface interviews were used. Multi stage cluster sampling was used to select the sample.

Results Data were collected from 171,366 rural and urban households, covering a population of 819,429 . The overall incidence of RTIs fatality was 12.9 per 100,000 population. The mortality rate gradually rose from children under 5 and peaked in the older age group, 55 years and above, $(21.4$ per 100,000$)$. The overall rate of non-fatal RTI was calculated as 134.5 per 100,000 . The highest incidence (165.7 per 100,000$)$ was in the $20-39$ years age group. A significantly higher rate of RTI mortality and morbidity was observed among males. The incidence of RTI was found to be three times higher in rural than urban areas. Most RTIs were non motorised vehicle and pedestrian injuries. The highest rate of RTI disability was found among males, aged 30-54 years.

Conclusion Road traffic injury is an important public health issue in Bangladesh. Immediate attention should be made to strengthen preventive intervention measures.

\section{Occupational safety}

\section{Parallel Mon 2.4}

\section{AGRICULTURAL SAFETY \& HEALTH MANAGEMENT PLANNING}

Dennis J Murphy. Penn State University, USA

\subsection{6/injuryprev-2016-042156.145}

Background Agricultural producers lack an easily understandable reference to help them develop a comprehensive safety and health plan for their operation. While many examples of safety management plans exist for general industry, they do not relate well to the hazards and risk of agriculture.

Objective To develop an agricultural safety and health management plan reference manual applicable to a wide range of agricultural operations.

Results The manual Safety and Health Management Planning for General Farm and Ranch Operations. The major sections of this 